\title{
Yin and Yang in Post-Translational Modifications of Human D-Amino Acid Oxidase
}

\author{
Silvia Sacchi *, Valentina Rabattoni, Matteo Miceli and Loredano Pollegioni \\ "The Protein Factory 2.0", Dipartimento di Biotecnologie e Scienze della Vita, Università degli Studi Dell'Insubria, Varese, Italy
}

OPEN ACCESS

Edited by:

Claudio D'Amore,

University of Padua, Italy

Reviewed by:

Hisashi Mori,

University of Toyama, Japan

Darrick Balu,

McLean Hospital, United States Herman Wolosker,

Technion Israel Institute of

Technology, Israel

*Correspondence:

Silvia Sacchi

silvia.sacchi@uninsubria.it

Specialty section:

This article was submitted to

Cellular Biochemistry,

a section of the journal

Frontiers in Molecular Biosciences

Received: 24 March 2021 Accepted: 23 April 2021

Published: 10 May 2021

Citation:

Sacchi S, Rabattoni V, Miceli M and Pollegioni L (2021) Yin and Yang in Post-Translational Modifications of Human D-Amino Acid Oxidase.

Front. Mol. Biosci. 8:684934. doi: 10.3389/fmolb.2021.684934
In the central nervous system, the flavoprotein D-amino acid oxidase is responsible for catabolizing $\mathrm{D}$-serine, the main endogenous coagonist of $\mathrm{N}$-methyl-D-aspartate receptor. Dysregulation of $\mathrm{D}$-serine brain levels in humans has been associated with neurodegenerative and psychiatric disorders. This D-amino acid is synthesized by the enzyme serine racemase, starting from the corresponding L-enantiomer, and degraded by both serine racemase (via an elimination reaction) and the flavoenzyme D-amino acid oxidase. To shed light on the role of human D-amino acid oxidase (hDAAO) in D-serine metabolism, the structural/functional relationships of this enzyme have been investigated in depth and several strategies aimed at controlling the enzymatic activity have been identified. Here, we focused on the effect of post-translational modifications: by using a combination of structural analyses, biochemical methods, and cellular studies, we investigated whether hDAAO is subjected to nitrosylation, sulfhydration, and phosphorylation. hDAAO is S-nitrosylated and this negatively affects its activity. In contrast, the hydrogen sulfide donor NaHS seems to alter the enzyme conformation, stabilizing a species with higher affinity for the flavin adenine dinucleotide cofactor and thus positively affecting enzymatic activity. Moreover, hDAAO is phosphorylated in cerebellum; however, the protein kinase involved is still unknown. Taken together, these findings indicate that $\mathrm{D}$-serine levels can be also modulated by post-translational modifications of hDAAO as also known for the D-serine synthetic enzyme serine racemase.

Keywords: D-serine, flavoprotein, nitrosylation, phosphorylation, biochemical properties, sulfhydration

\section{INTRODUCTION}

The FAD-dependent enzyme D-amino acid oxidase (DAAO, EC 1.4.3.3) catalyzes the degradation of D-amino acids, the only exception being aspartate and glutamate (Pollegioni et al., 2007). In mammals, DAAO is mainly expressed in kidney, liver, brain, and gut (D'Aniello et al., 1993; Koga et al., 2017). In the brain, D-serine (D-Ser) represents the physiological substrate of DAAO. Indeed, $\mathrm{D}$-Ser is the main endogenous coagonist of the N-methyl-D-aspartate type among the glutamate

\footnotetext{
Abbreviations: BSA (bovine serum albumin), CBS (cystathionine $\beta$-synthase), CREB1 (cAMP-responsive element-binding protein 1), DAAO (D-amino acid oxidase), D-Ser (D-serine), DTNB (5,5'-dithiobis-(2-nitrobenzoic acid)), ERK (extracellular signal regulated kinase), FAD (flavin adenine dinucleotide), GSH (reduced glutathione), GSNO (S-nitrosoglutathione), GSSG (oxidized glutathione), hDAAO (human DAAO), IP (immunoprecipitation), MMTS (methyl methanethiosulfonate), NMDAr (N-methyl-D-aspartate receptor, NO (nitric oxide), NOS (nitric oxide synthase), PKA (cAMP-dependent protein kinase), PKC (protein kinase C), SAS (solvent accessible surface area), SDS-PAGE (sodium dodecyl sulfate-polyacrylamide gel electrophoresis), SNO-Cys (S-nitrosylated cysteine), SR (serine racemase)
} 
receptors (NMDAr): it binds the glycine site of these receptors, which regulate activity (Mothet et al., 2000) and physiological functions (Collingridge et al., 2013). Any dysregulation in the processes tuning D-Ser concentration alters NMDAr transmission and is thus involved in the mechanisms underlying various diseases of the central nervous system, such as amyotrophic lateral sclerosis, Alzheimer's disease, schizophrenia, etc. (Collingridge et al., 2013; Paul and de Belleroche, 2014; Guercio and Panizzutti, 2018; Kondori et al., 2018; Uno and Coyle, 2019; Ploux et al., 2020). D-Ser metabolism in the brain is due to the activity of two enzymes: in addition to DAAO, serine racemase (SR, EC 5.1.1.18) catalyzes both the synthesis of $\mathrm{D}$-Ser from the $\mathrm{L}$-enantiomer and its degradation via an $\alpha, \beta$-elimination reaction (Wolosker et al., 1999). In astrocytes, DAAO is the main enzyme involved in D-Ser catabolism since SR is only marginally expressed.

During the past few years, the structural-functional relationships in human DAAO (hDAAO) have been investigated using the recombinant protein produced in $E$. coli (Sacchi et al., 2012; Murtas et al., 2017; Pollegioni et al., 2018) and selected cell systems (Cappelletti et al., 2015; Murtas et al., 2019). Based on present knowledge, five strategies for regulating hDAAO have been identified:

(i) FAD binding: hDAAO possesses a weak interaction with FAD. The dissociation constant $\left(\mathrm{K}_{\mathrm{d}}\right)$ is in the micromolar range (Molla et al., 2006; Caldinelli et al., 2009), a value corresponding to the in vivo concentration of cofactor (Decker and Byerrum, 1954; Leighton et al., 1982). Accordingly, at conditions resembling physiological ones, hDAAO is present as an equilibrium between the apoprotein and the active holoenzyme;

(ii) substrate/ligand binding: the presence of a ligand in the active site promotes FAD binding $\left(\mathrm{K}_{\mathrm{d}}\right.$ decreases from 8 to $0.3 \mu \mathrm{M}$ in the presence of $1 \mathrm{mM}$ benzoate) (Molla et al., 2006; Caldinelli et al., 2010). We have suggested that substrate binding pushes its own degradation by increasing the amount of hDAAO active holoenzyme form in solution. Moreover, we recently demonstrated that hDAAO apoprotein exists in two alternative conformations differing in flavin cofactor affinity: the equilibrium is shifted toward the one at higher avidity by the presence of an active-site ligand (Murtas et al., 2017);

(iii) protein interaction: pLG72, bassoon, and PEX5 proteins have been reported to bind hDAAO (Sacchi et al., 2008; Popiolek et al., 2011; Sacchi et al., 2011; Maier et al., 2018). The primate-specific pLG72 protein in particular, appears to act as a negative chaperone of hDAAO, resulting in enzyme inactivation and higher instability (Sacchi et al., 2011). Notably, such an interaction has been related to schizophrenia susceptibility (Chumakov et al., 2002; Sacchi et al., 2016);

(iv) subcellular localization: cellular studies showed that part of the overexpressed hDAAO in U87 glioblastoma cells is cytosolic (Sacchi et al., 2011; Cappelletti et al., 2014). Indeed, recent reports on rats demonstrated that DAAO is present both in the cytosol and nuclei of proximal tubule epithelial cells following treatment with the drug propiverine (Luks et al., 2017b). A putative nuclear translocation signal has been identified in the primary sequence of hDAAO that could facilitate nuclear import via importin 7 after a TPx sequence has been phosphorylated (Luks et al., 2017a);

(v) post-translational modifications: it has been proposed that nitrosylation regulates hDAAO (Shoji et al., 2006) as its activity in U87 cells was enhanced by nitric oxide (NO) in a dose-dependent manner. The authors proposed that NO might accelerate D-Ser elimination in astrocytes by inhibiting SR and by activating hDAAO. Moreover, the observation that $\mathrm{D}$-Cys represents the best substrate for the flavoenzyme (Murtas et al., 2017) and that DAAO and 3-mercapto-pyruvate sulfurtransferase are involved in generating $\mathrm{H}_{2} \mathrm{~S}$ (Shibuya et al., 2013) suggests that $\mathrm{H}_{2} \mathrm{~S}$ and/or sulfhydration might also affect hDAAO function.

Here, we focused on the modulation of hDAAO activity by three post-translational modification processes (nitrosylation, sulfhydration, and phosphorylation) with the aim to help elucidate the physiological functioning and alteration of this enzyme in pathological states.

\section{MATERIALS AND METHODS}

\section{Recombinant Proteins}

The cDNA coding for hDAAO was cloned in the pET11b expression plasmid, under control of the $\mathrm{T} 7$ promoter. The His-tagged recombinant protein was expressed in E. coli BL21 (DE3) cells (Invitrogen, Carlsbad, CA, United States) upon induction with IPTG during the exponential phase of growth and purified by HiTrap chelating chromatography (GE Healthcare, Boston, MA, United States), as reported in (Murtas et al., 2017). For long storage at $-80^{\circ} \mathrm{C}$, the final protein preparation was equilibrated in $20 \mathrm{mM}$ Tris- $\mathrm{HCl}$ buffer, $100 \mathrm{mM} \mathrm{NaCl}, \mathrm{pH} 8.0$, $10 \%$ glycerol, and $5 \mathrm{mM} 2$-mercaptoethanol, to which $40 \mu \mathrm{M}$ FAD was added. The concentration of the purified enzyme was determined using the extinction coefficient at $455 \mathrm{~nm}$ (12.2 $\mathrm{mM}^{-1} \mathrm{~cm}^{-1}$ ) (Molla et al., 2006).

\section{Molecular Modeling and Structural Analyses}

Solvent-accessible surface area analysis was performed on the hDAAO dimer structure (pdb code 2E49) using the algorithm provided by the Pymol open-source software (https://pymol. org/2/), which usually defines this parameter as the surface traced out by the center of a water sphere, having a certain radius rolled over the protein atoms; here, a default radius of about $1.4 \AA$ was set.

\section{Cell Cultures}

The U87 human glioblastoma cell line stably expressing hDAAO was generated by cloning the encoding cDNA in the pcDNA3 
vector by restriction digestion: hDAAO cDNA was excised from pEYFP-hDAAO_C3 (Sacchi et al., 2011) using the HindIII and EcoRI sites. The resulting construct was confirmed by automated sequencing. U87 cells (ATCC, Manassas, VA, United States) were maintained in DMEM supplemented with $10 \%$ fetal bovine serum, $1 \mathrm{mM}$ sodium pyruvate, $2 \mathrm{mML}$-glutamine, penicillin/ streptomycin, and amphotericin B (Euroclone S.p.A., Pero, Italy) at $37^{\circ} \mathrm{C}$ in a $5 \% \mathrm{CO}_{2}$ (Sacchi et al., 2008). Transfection mixtures were set up using $6 \mu \mathrm{L}$ of FuGENE HD transfection reagent (Promega Co., Madison, WI, United States) and $2 \mu \mathrm{g}$ of the pcDNA3_hDAAO plasmid. Stable cell clones were selected by adding $0.4 \mathrm{mg} / \mathrm{mL} \mathrm{G418}$ to the growth medium. In the selected cell clones, hDAAO expression levels were monitored by Western blot analysis.

\section{Determination of Accessible Cysteines}

To evaluate the number of accessible cysteines in hDAAO, the holo- and apoprotein forms were reacted with $0.1 \mathrm{mM}$ DTNB in $0.45 \mathrm{M}$ sodium phosphate buffer, $\mathrm{pH} 8.0,0.45 \mathrm{mM}$ EDTA, either under native conditions or in the presence of $4 \mathrm{M}$ urea (Pollegioni et al., 1997). Samples were incubated for $15 \mathrm{~min}$ at room temperature and then the absorbance at $412 \mathrm{~nm}$ was recorded. Free sulfhydryl groups were quantified using the molar extinction coefficient of 2-nitro-5-thiobenzoic acid (TNB, $\varepsilon_{412} \mathrm{~nm}=14,150$ and $14,290 \mathrm{M}^{-1} \mathrm{~cm}^{-1}$ in sodium phosphate buffer and $4 \mathrm{M}$ urea, respectively) and a calibration curve obtained using different concentrations of L-cysteine $(0-200 \mu \mathrm{M})$.

\section{In vitro S-Nitrosylation}

In order to ensure the long storage stability of recombinant purified enzyme, 2-mercaptoethanol was added to the storage buffer; the reducing agent was removed to perform in vitro modification studies. Thus, aliquots of hDAAO preparations were 10 -fold diluted in nonreducing storage buffer $(20 \mathrm{mM}$ Tris- $\mathrm{HCl} \mathrm{pH} 8.0,100 \mathrm{mM} \mathrm{NaCl}, 10 \%$ glycerol, and $40 \mu \mathrm{M}$ FAD) and concentrated to the starting volume using an Amicon centrifugal filter device (Ultracel-30K, Merck, Burlington, MA, United States). The procedure was repeated twice and protein concentration was determined spectrophotometrically.

In vitro nitrosylation was performed by incubating recombinant hDAAO with S-nitrosoglutathione (GSNO) as the NO donor (Wang et al., 2011). Reaction mixtures were prepared by diluting the protein in HEN buffer $(25 \mathrm{mM}$ HEPES, $1 \mathrm{mM}$ EDTA, $0.1 \mathrm{mM}$ neocuproine) to a final concentration of $1 \mathrm{mg} / \mathrm{mL}(25 \mu \mathrm{M})$ and adding $500 \mu \mathrm{M}$ GSNO $(200 \mu \mathrm{L}$ final volume), in the presence or absence of $40 \mu \mathrm{M}$ FAD. Mixtures containing $1 \mathrm{mg} / \mathrm{mL}$ BSA (reported to be S-nitrosylated by NO donors) (Stamler et al., 1992) or the recombinant protein to which $500 \mu \mathrm{M}$ reduced glutathione $(\mathrm{GSH})$ or oxidized glutathione (GSSG) was added were prepared as controls. Reaction mixtures were incubated $1 \mathrm{~h}$ in the dark, at $25^{\circ} \mathrm{C}$, under constant rotation. S-Nitrosylation was verified by fluorescence detection using the fluorescence switch assay, following SDS-PAGE separation. The fluorescence switch assay was set up by using the fluorescent probe Alexa Fluor 350 C5 Maleimide (Molecular Probes/ThermoFisher Scientific,
Waltham, MA, United States; excitation and emission wavelengths of 345 and $444 \mathrm{~nm}$, respectively) and a procedure modified from (Han et al., 2008). The excess of GSNO (or GSH, or GSSG) was removed from the reaction mixtures by three steps of concentration/dilution in HEN buffer using Amicon Ultra $30 \mathrm{~K} 0.5 \mathrm{ml}$ centrifugal filters (Merck). Unmodified free thiols were saturated by reacting the proteins with $20 \mathrm{mM}$ MMTS in the presence of $2.5 \% \mathrm{SDS}$ for $30 \mathrm{~min}$ at $50^{\circ} \mathrm{C}$. MMTS was removed by 4 concentration/dilution steps in HEN buffer, as described above. Nitrosylated thiols were reduced by incubating the mixtures for $1 \mathrm{~h}$ at room temperature upon adding $5 \mathrm{mM}$ sodium ascorbate and labeled with $50 \mu \mathrm{M}$ Alexa Fluor $350 \mathrm{C} 5$ Maleimide at $4^{\circ} \mathrm{C}$ for one night. Labeled samples were analyzed by SDS-PAGE under nonreducing conditions. The gel was rinsed with MilliQ water and imaged on a transilluminator using a Gel Doc 2000 (Biorad, Hercules, CA, United States). During the entire procedure samples were protected from light, in order to avoid dissociation of the modified thiols. Positive controls were prepared by omitting the MMTS blocking step, so that all cysteines were reduced during the incubation with sodium ascorbate.

\section{In vitro Sulfhydration}

The modification of cysteine residues in hDAAO by $\mathrm{H}_{2} \mathrm{~S}$ was investigated by incubating the recombinant protein with NaHS (Sigma-Aldrich, St. Louis, MO, United States) as a hydrogen sulfide donor. The protein samples were diluted in storage buffer without 2-mercaptoethanol to a concentration of $1 \mathrm{mg} / \mathrm{mL}$, to which $1 \mathrm{mM} \mathrm{NaHS}$ was added, and incubated at $37^{\circ} \mathrm{C}$ for $1 \mathrm{~h}$. The presence of modified cysteines was analyzed by performing the fluorescence switch assay following nonreducing SDS-PAGE, as detailed above.

\section{Cellular Nitrosylation and Sulfhydration Studies}

The U87 stable cell clone ectopically expressing hDAAO was used to investigate the effect of nitrosylation and sulfhydration on enzyme cellular activity, while cells transfected with the empty pcDNA3 vector were used as controls. Cells were maintained in T75 flasks; when the cell density reached $\sim 80 \%$ of confluence, they were washed in PBS and $10 \mathrm{~mL}$ of serum free DMEM containing $50 \mu \mathrm{M}$ of either NOC7 or NOR3 as NO donors, or a corresponding amount of vehicle, was added (Santa Cruz Biotechnology, Dallas, TX, United States) and they were placed back in $5 \% \mathrm{CO}_{2}$ at $37^{\circ} \mathrm{C}$ for $2 \mathrm{~h}$. Treated and control cells were then collected by trypsinization, centrifuged, washed rapidly with ice-cold PBS, and assayed for hDAAO activity. Lysates were prepared by suspending treated and control cells in $50 \mathrm{mM}$ sodium phosphate, $\mathrm{pH} 7.0,0.7 \mu \mathrm{g} / \mathrm{mL}$ pepstatin, $1 \mu \mathrm{g} /$ $\mathrm{mL}$ leupeptin, $10 \mu \mathrm{M} F A D$, and $0.1 \%$ ethanol and then sonicating the cell suspension ( 3 cycles, $10 \mathrm{~s}$ each, intersperse with $30 \mathrm{~s}$ in ice). Samples were clarified by centrifugation $(13,000 \times \mathrm{g}$, for $15 \mathrm{~min}$ at $4^{\circ} \mathrm{C}$ ), and total protein content was quantified by using the Bradford reagent (Sigma-Aldrich). Amounts of treated and control cell lysates corresponding to $50 \mu \mathrm{g}$ of total proteins were used to measure hDAAO activity, on a 96 -well plate by using the 
Amplex UltraRed assay as previously reported (Sacchi et al., 2011), see Activity assays section, below.

The same procedure was used to assess the effect of sulfhydration on hDAAO cellular activity. In this case, cells were treated for $30 \mathrm{~min}$ with $50 \mu \mathrm{M} \mathrm{NaHS}$, as a hydrogen sulfide donor.

\section{In vitro Phosphorylation}

Reaction mixtures were prepared in a final volume of $50 \mu \mathrm{L}$ using three protein kinases. The PKA reaction mixture contained $3.4 \mu \mathrm{M} \quad(6.8 \mu \mathrm{g}, \quad 0.17$ nmoles $)$ of recombinant $\mathrm{hDAAO}$ in $50 \mathrm{mM}$ Tris, $\mathrm{pH} 7.5,50 \mu \mathrm{M} \mathrm{ATP}, 10 \mathrm{mM} \mathrm{MgCl}_{2}$, and $1 \mathrm{mM}$ DTT. Alternatively to hDAAO, $4 \mu \mathrm{g}$ of the recombinant GSTtagged CREB1 (Merk Millipore; $59 \mathrm{kDa}, 0.11$ nmoles, $2.2 \mu \mathrm{M}$ ) was used as a positive control (Gonzalez and Montminy, 1989). Then, $0.009 \mathrm{U}$ of recombinant PKA (Merck) was diluted in $50 \mathrm{mM}$ HEPES, pH 7.4, $1 \mathrm{mM}$ DTT, and added to each assay mixture to start the reaction. Analogously, PKC- $\alpha$ and PKC- $\varepsilon$ (Ab Cam, Cambridge, United Kingdom) reaction mixtures contained $6.8 \mu \mathrm{g}$ of recombinant hDAAO in $20 \mathrm{mM}$ HEPES, $\mathrm{pH} 7.4,50 \mu \mathrm{M}$ ATP, $10 \mathrm{mM} \mathrm{MgCl}_{2}, 1 \mathrm{mM} \mathrm{CaCl}_{2}, 0.5 \mathrm{mg} / \mathrm{mL}$ phosphatidylserine, $0.05 \mathrm{mg} / \mathrm{mL}$ diacylglycerol, $1 \mathrm{mM}$ sodium orthovanadate, and $1 \mathrm{mM}$ DTT. In these cases, positive controls used the histone H1 (Sigma-Aldrich, $4 \mu \mathrm{g}, 0.19$ nmoles, $3.8 \mu \mathrm{M}$ ) (Zhao et al., 2004). The recombinant PKC- $\alpha$ and PKC- $\varepsilon$ were diluted in $65 \mathrm{mM}$ Tris$\mathrm{HCl}, \mathrm{pH} 7.5,0.87 \% \mathrm{NaCl}(\mathrm{w} / \mathrm{v}), 2 \mathrm{mM}$ DTT; $0.001 \mathrm{U}$ of PKC- $\alpha$ or $0.0005 \mathrm{U}$ of $\mathrm{PKC}-\varepsilon$ was added to start the reaction. All reactions were carried out at $30^{\circ} \mathrm{C}$ and sample aliquots $(15 \mu \mathrm{L}, 2 \mu \mathrm{g}$ hDAAO $)$ were collected at time $0,2 \mathrm{~h}$, and overnight and then blocked by adding $4 \mathrm{X}$ Laemmli sample buffer $(5 \mu \mathrm{L})$ and boiling. The different samples were resolved by SDS-PAGE and phosphorylated proteins detected by using the Pro-Q Diamond Phosphoprotein Gel Stain (Thermo Fisher Scientific), following the procedure indicated by the supplier. As a staining control, a molecular ladder (PeppermintStick Phosphoprotein Molecular Weight Standards, Thermo Fisher Scientific) containing phosphorylated (45.0 and $23.6 \mathrm{kDa})$ and not phosphorylated (116, 66.2, 18.0, and $14.4 \mathrm{kDa}$ ) proteins was used. Gels were imaged using an Odissey Fc imaging system (LI-COR Biotechnology, Lincoln, United States) and the $600-\mathrm{nm}$ channel with a light source for excitation.

\section{Tissue Analysis of Human D-Amino Acid Oxidase Phosphorylation Levels}

The hDAAO endogenously present in human brain tissues (cerebellum and prefrontal cortex obtained from the London Neurodegenerative disease Brain Bank, King's College, London, United Kingdom) was isolated by immunoprecipitation (IP). Tissue samples were from a healthy, male subject, 58 years of age (PMD $20 \mathrm{~h}$ ). Briefly, 100-120 mg were resuspended in lysis buffer: $20 \mathrm{mM}$ Tris- $\mathrm{HCl}, \mathrm{pH} 8.0,150 \mathrm{mM} \mathrm{NaCl}, 0.5 \% \mathrm{NP}-40$, $1 \mathrm{mM}$ EDTA, $2 \mu \mathrm{M}$ leupeptin, $1 \mu \mathrm{M}$ pepstatin, $500 \mu \mathrm{M}$ PMSF, and phosphatase Inhibitor Cocktail (Cell Signaling Technologies, Danvers, MA, United States), homogenized with a microcentrifuge tube potter, and sonicated (3 cycles, $20 \mathrm{~s}$ each, interspersed with 1-min incubation in ice). Lysates were clarified by centrifugation $\left(13,000 \times \mathrm{g}\right.$ for $30 \mathrm{~min}$ at $\left.4^{\circ} \mathrm{C}\right)$ and the total protein concentration in the supernatants (Pre-IP samples) was quantified using the Bradford assay (Sigma-Aldrich). Equivalent amounts of samples (1.5 mg total proteins) were subjected to immunoprecipitation, which was performed by crosslinking rabbit polyclonal anti-hDAAO antibodies (10 $\mu$ g, Davids Biotechnologie, Regensburg, Germany) to Dynabeads Protein G (Invitrogen, Carlsbad, CA, United States) using $20 \mathrm{mM}$ dimethyl pimelimidate dissolved in $0.2 \mathrm{M}$ triethanolamine, $\mathrm{pH}$ 8.2 (30 $\mathrm{min}$ at room temperature under rotation). Negative controls were set up by omitting the antibodies in the crosslinking reaction. After removing the excess of crosslinker, the antibody-crosslinked Dynabeads were incubated with the lysate samples overnight at $4^{\circ} \mathrm{C}$, under rotation. The supernatants (post-IP samples) were collected by separating the beads on the magnet, which were then extensively washed with lysis buffer and finally suspended in $55 \mu \mathrm{L}$ of a nonreducing $1 X$ Laemmli sample buffer (IP sample) and boiled. To confirm the presence of hDAAO, $10 \mu \mathrm{L}$ of the IP samples were analyzed by Western blotting, while the remaining samples $(40 \mu \mathrm{L})$ were resolved by SDS-PAGE and imaged using the Pro-Q Diamond Gel Stain to detect the phosphorylation levels of the immunoprecipitated hDAAO.

Western blot analyses were performed using the anti-hDAAO primary antibody (1:1,000, Davids Biotecnologie) and a peroxidaseconjugated donkey anti-rabbit IgG secondary antibody $(1: 15,000$, Jackson ImmunoResearch, Ely, United Kingdom).

\section{Activity Assays}

Following in vitro nitrosylation and sulfhydration, hDAAO activity was assayed polarographically using an oxygen electrode (Molla et al., 2006). Aliquots withdrawn from the reaction mixtures were diluted in the storage buffer without 2mercaptoethanol (1:10) and immediately assayed for residual activity with an oxygen electrode at $\mathrm{pH} 8.5$, air saturation, and $25^{\circ} \mathrm{C}$, using $28 \mathrm{mM} \mathrm{D}$-alanine as substrate in the presence of $0.2 \mathrm{mM}$ FAD. Control measurements were performed in the absence of NO or $\mathrm{H}_{2} \mathrm{~S}$ donors. The residual enzymatic activity was calculated by comparing the values measured before and after performing the in vitro modification reactions. The statistical significance of data was assessed by means of an unpaired $t$-test, $n=5$.

The effect of either nitrosylation or sulfhydration on hDAAO functionality was also investigated at the cellular level. U87 cells ectopically expressing hDAAO were treated with the NO donors NOR-3 (50 $\mu \mathrm{M}$ for $2 \mathrm{~h}$ ), as reported in (Shoji et al., 2006) or NOC7 (50 $\mu \mathrm{M}$ for $2 \mathrm{~h}$ ), or with the hydrogen sulfide donor NaHS $(100 \mu \mathrm{M}$ for $30 \mathrm{~min})$, or an equal amount of vehicle (DMSO and $\mathrm{H}_{2} \mathrm{O}$, respectively). Upon treatments, the enzyme activity was assayed on cell lysates by using the Amplex UltraRed reagent (Invitrogen, Carlsbad, CA, United States) as reported in (Sacchi et al., 2011). The reaction was started by diluting cell lysates $1: 2$ in the activity assay solution containing $50 \mu \mathrm{M}$ Amplex UltraRed, $0.2 \mathrm{U} / \mathrm{ml}$ horseradish peroxidase, $10 \mathrm{mM} \mathrm{NaN}_{3}, 10 \mu \mathrm{M} \mathrm{FAD}$, and $50 \mathrm{mM}$ D-Ser in $50 \mathrm{mM}$ sodium phosphate, $\mathrm{pH}$ 7.0. The assay is based on the detection of $\mathrm{H}_{2} \mathrm{O}_{2}$ by peroxidase-mediated oxidation of the fluorogenic Amplex UltraRed Dye. Negative controls were performed using the activity assay solution lacking the 
substrate $\mathrm{D}$-Ser. hDAAO activity was determined by monitoring the fluorescence emission at $590 \mathrm{~nm}$ (upon excitation at $535 \mathrm{~nm}$ ) over time (50 $\mathrm{min}$ ) and comparing the difference in fluorescence emission between samples (from cells treated with the $\mathrm{NO}$ or $\mathrm{H}_{2} \mathrm{~S}$ donors) and control assay mixtures. U87 cells transfected with the pcDNA3 empty vector were used as further control. Data significance was evaluated by means of a two-way analysis of variance (ANOVA) and a multiple $t$-test on grouped measures: 4 measurements were performed at each time point and the experiment was repeated twice.

\section{Spectral Measurements}

hDAAO apoprotein was prepared by overnight dialysis of the holoenzyme against $1 \mathrm{M} \mathrm{KBr}$ as reported in (Murtas et al., 2019) and the final concentration was determined based on the extinction coefficient at $280 \mathrm{~nm}\left(75.2 \mathrm{mM}^{-1} \mathrm{~cm}^{-1}\right)$. Fluorescence spectra were measured at $1 \mu \mathrm{M}$ protein concentration $(0.04 \mathrm{mg} / \mathrm{mL})$ in $50 \mathrm{mM}$ sodium pyrophosphate, $\mathrm{pH} 8.3$, and 5\% glycerol; spectra were recorded using a Jasco FP-750 instrument and corrected for the buffer contribution. Protein fluorescence spectra were recorded between 300 and $400 \mathrm{~nm}$, with excitation at $280 \mathrm{~nm}$.

The ligand dissociation constants were estimated by titrating the apoprotein with increasing amounts of FAD and following the quenching of protein fluorescence at 330-340 nm (Molla et al., 2006). The $\mathrm{K}_{\mathrm{d} \text {,FAD }}$ values were determined in the presence of different concentrations of the NO donor GSNO or the $\mathrm{H}_{2} \mathrm{~S}$ donor NaHS. In vitro nitrosylation mixtures containing
hDAAO apoprotein $(1 \mathrm{mg} / \mathrm{mL}, 25 \mu \mathrm{M})$ were prepared in $100 \mu \mathrm{L}$ $50 \mathrm{mM}$ sodium pyrophosphate $\mathrm{pH} 8.3,5 \%$ glycerol, $0.1 \mathrm{mM}$ neocuproine, and 50 or $500 \mu \mathrm{M}$ GSNO and incubated for $1 \mathrm{~h}$ in the dark, at $25^{\circ} \mathrm{C}$, under constant rotation. Mixtures were then diluted 25 -fold in the same buffer $(1 \mu \mathrm{M}$ apoprotein final concentration) and transferred to the cuvette for titration with FAD. To assess the effect of the hydrogen sulfide donor, mixtures containing hDAAO apoprotein $(1 \mu \mathrm{M})$ were set up in $20 \mathrm{mM}$ Tris- $\mathrm{HCl}$ buffer, $100 \mathrm{mM} \mathrm{NaCl}, \mathrm{pH} 8.0$, and $10 \%$ glycerol to which 5 or $40 \mu \mathrm{M}$ NaHS was added and incubated $30 \mathrm{~min}$ at room temperature before titration. Control experiments were performed by omitting the modifying agents. In all cases, $\mathrm{K}_{\mathrm{d}, \mathrm{FAD}}$ values were estimated by hyperbolic interpolation of the experimental data (Murtas et al., 2017).

\section{RESULTS \\ Prediction of Secondary Modification Sites in hDAAO}

Although NO has been proposed to positively affect hDAAO activity in U87 human glioblastoma cells in a dose-dependent manner (Shoji et al., 2006), the observed effect has not been investigated further, nor has the modification of cysteine residues by S-nitrosylation been evaluated. hDAAO contains five cysteines residues (Figure 1). Four cysteines are conserved in both hDAAO
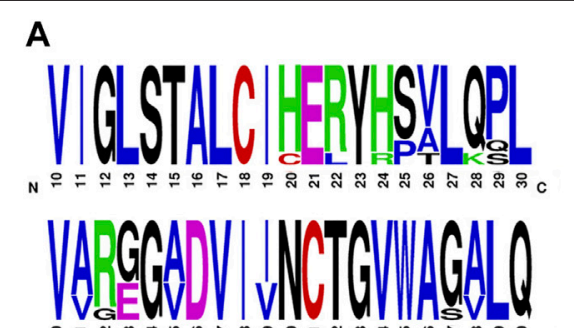

N

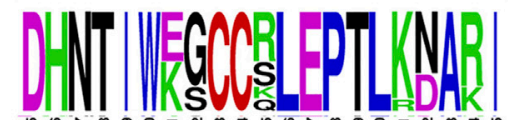

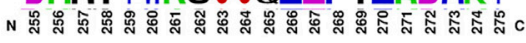

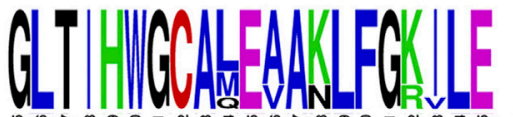

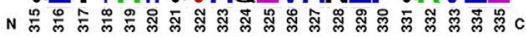

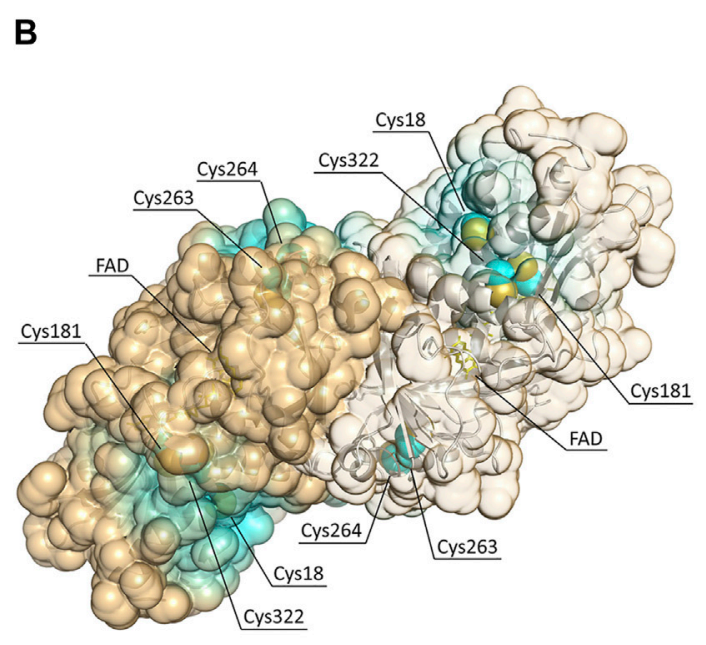

C
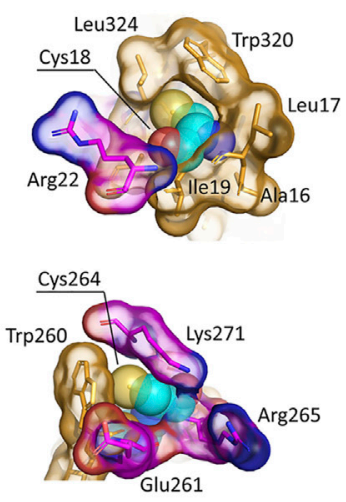

FIGURE 1 | Cysteine residues in hDAAO. (A) Weblogo representation of conserved residues identified by the alignment of DAAO sequences from Homo sapiens, Mus musculus, Rattus norvegicus, Sus scrofa, Bos taurus, Cavia porcellus, and Macaca fascicularis. The $x$-axis represents amino acid positions (the annotated numbering refers to the human enzyme). The height of symbols is proportional to the degree of conservation of single residues. Panels represent sequence stretches of 20 residues containing cysteine residues, shown in red. Five cysteine residues appear highly conserved in mammalian DAAOs. Figure prepared using WebLogo (https://weblogo.berkeley.edu/logo.cgi). (B) Solvent-accessible surface (SAS) as calculated for the hDAAO dimer (pdb code 2E49). Cysteine residues are represented as sphere (carbon atoms in cyan, sulfur atoms in yellow), the FAD cofactor is represented as sticks (yellow), and the backbone is shown as cartoon. Protein surface is colored by proximity of cysteine residues (cyan = cysteine residues located within $5 \AA$ from the surface; orange= cysteine residues located at a distance higher than $15 \AA$ from the surface). SAS has been calculated based on a solvent radius of $1.4 \AA$. Two of the conserved cysteine residues are likely accessible to modifications. (C) Details showing the amino acidic environment of selected cysteine residues, represented as spheres (carbon atoms in cyan, sulfur atoms in yellow, nitrogen atoms in blue, and oxygen atoms in red). The surrounding residues are depicted as sticks; the van der Waals surface is shown. Hydrophobic residues are colored in orange, while charged residues are colored by element (carbon atoms in magenta, nitrogen atoms in blue, and oxygen atoms in red). Illustrations prepared with "The Protein Imager online molecular viewer" (https://3dproteinimaging.com/protein-imager/). 
and the homologous flavoenzyme human D-aspartate oxidase (containing a total of nine cysteines).

Putative nitrosylated residues in hDAAO were predicted by using different web-based tools (Table 1): these analyses yielded divergent results. It is noteworthy that the web-based tool SNOsite (Lee et al., 2011), which applies the maximal dependence decomposition approach to explore conserved nitrosylation motifs, identified the totality of hDAAO cysteines as potential nitrosylation sites (Table 1). In native hDAAO, all cysteine residues should be present in the free reduced form as no disulfide bonds were apparent in the crystal structure (pdb 2E49) and have been identified in the - $\mathrm{SH}$ state by the disulfide bondingstate predictors DISULFIND at http://disulfind.dsi.unifi.it/ (Ceroni et al., 2006) and CYSPRED at http://gpcr.biocomp. unibo.it/cgi/predictors/cyspred/pred_cyspredcgi.cgi (Fariselli et al., 1999).

For protein S-sulfhydration (Mustafa et al., 2009), it is currently not feasible to predict putative modification sites, although accumulated evidence suggests that this modification may share chemical features with protein S-nitrosylation.

Phosphorylation sites were also predicted by means of computational tools (Table 2). Although several residues in hDAAO were identified as "modified" by the different predictors, the estimated levels of serine, threonine, and tyrosine phosphorylation were heterogeneous. Moreover, in the case of DIPHOSPH 1.3, no phosphorylation site was identified when the group predictor for human was selected instead of the default predictor. Nonetheless, hDAAO phosphorylation at Tyr23 is documented in PhosphoSitePlus (https://www.phosphosite.org). When single kinases are specified as the putative modifying enzyme, hDAAO appeared to be mainly subjected to phosphorylation by cAMP-dependent protein kinase (PKA), protein kinase $\mathrm{C}$ (PKC), and protein kinases involved in cell cycle regulation (cdk5 and CKII).

\section{Two Cysteines are Solvent Accessible in hDAAO}

The extent to which an amino acid interacts with the solvent and the protein core is proportional to the degree of exposition to these environments. The solvent-accessible surface area (SAS) is a geometric measure of this exposure, and therefore a correlation exists between SAS and environment-free energy (Pokala and Handel, 2004; Vizcarra and Mayo, 2005). The exposure of cysteines to modification was assessed by performing a solvent-accessible surface analysis on the protein structure (Figure 1B). In hDAAO, Cys18 and Cys264 appear to be exposed on the protein surface, while the other three cysteine residues point toward the interior of the protein structure and thus are less likely accessible to modification (Figure 1B). Notably, Cys18 is surrounded by hydrophobic residues (Figure 1C, top) and is located at $8.2 \AA$ from $\operatorname{Arg} 22$, which is part of a putative nitrosylation motif consensus sequence (Table 1): these two features might stabilize the S-nitrosylated cysteine residues (SNO-Cys) once modified (Marino and Gladyshev, 2010). Worthy of note is that hDAAO cysteines appear to be grouped in small clusters (Figure 1B).

The solvent accessibility of cysteine residues was experimentally evaluated by reacting the recombinant hDAAO with 5,5'-dithiobis (2-nitrobenzoic acid) (DTNB) under nonreducing conditions and in the absence or presence of a denaturing agent. Consistent with structural information, the reaction of native $\mathrm{hDAAO}$ with $\mathrm{DTNB}$ yielded $1.85 \pm 0.2$ free cysteines per protein monomer, whereas in the presence of $4 \mathrm{M}$ urea the assay yielded a number of $5.9 \pm 0.6$, indicating that three cysteines are not solvent accessible in the native conformation and confirming that no disulfide bonds are present. Notably, under native conditions the apoprotein and the holoenzyme forms of hDAAO exposed the same number of Cys $(1.9 \pm 0.2)$.

\section{Human D-Amino Acid Oxidase S-Nitrosylation Studies}

Cellular studies were performed on a U87 stable cell clone ectopically expressing hDAAO: cells were treated with the membrane-permeable NO donors NOC7 and NOR3 and activity assays were performed on the cell lysates using the fluorescent Amplex UltraRed reagent. Compared to control cells, significantly decreased fluorescence emission values were detected when cells were treated with NO donors (especially NOR3; treatment $\times$ time interaction $F(18,108)=29.47, p<$ 0.0001 and $\mathrm{F}(18,108)=11.8, p<0.0001$ for NOR3 and NOC7, respectively), while no signal changes were detected for lysates from cells transfected with the empty pcDNA3 vector, confirming the specificity of the assay (Figure 2A).

In vitro nitrosylation reaction mixtures were set up using pure, recombinant hDAAO solutions $(25 \mu \mathrm{M}$, depleted of the reducing agent 2-mercaptoethanol) and $500 \mu \mathrm{M}$ S-nitrosoglutathione

TABLE 1 | Prediction of nitrosylation sites by using web-based tools. Cysteine residues indicated in bold are strictly conserved in hDAAO. In the last column, underscored residues are those present in the consensus sequence of putative nitrosylation motifs as identified by the SNO site.

\begin{tabular}{|c|c|c|c|c|c|c|}
\hline \multirow[t]{2}{*}{ Cys position } & \multirow{2}{*}{$\frac{\text { GPS }}{\text { SNO } 1.0}$} & \multirow{2}{*}{$\frac{\text { iSNO }}{\text { PseAAC }}$} & \multirow{2}{*}{$\frac{\text { iSNO }}{\text { AAPair }}$} & \multirow{2}{*}{$\frac{\text { Deep }}{\text { Nitro }}$} & \multirow{2}{*}{$\frac{\text { SNO }}{\text { Site }}$} & Sequence \\
\hline & & & & & & -10 \\
\hline 18 & & & - & & - & AGVIGLSTALCIHERYHSVLQ \\
\hline 263 & & & & & • & IQDHNTIWĒGGCCRLEPTLKNA \\
\hline 264 & & - & & & $\bullet$ & QDĒNTIWEGGCCRLEPTLKNAR \\
\hline 322 & & & - & & - & GGYGLTIHWGCALEAAKLFGR \\
\hline
\end{tabular}

GPS SNO 1.0 at http://sno.biocuckoo.org (Xue et al., 2010); iSNO PseAAC at http://app.aporc.org/iSNO-PseAAC/(Xu et al., 2013a); iSNO AAPair at http://app.aporc.org/iSNO-AAPair/ (Xu et al., 2013b); DeepNitro at http://deepnitro.renlab.org/webserver.html (Xie et al., 2018); SNOSite at http://csb.cse.yzu.edu.tw/SNOSite/Prediction.html (Lee et al., 2011). 
TABLE 2 | Prediction of phosphorylation sites in hDAAO by using web-based tools. For netPhos 3.0 prediction, the score value was set above 0.75.

Residues (total number)

\section{Ser (15)}

Thr (22)

Tyr (12)
NetPhos 3.0

$4(27 \%)$
$5(22 \%)$
$2(17 \%)$

DIPHOSPH 1.3

$2(13 \%)$
$4(18 \%)$
$1(8 \%)$

PHOSPHONET

$$
\begin{aligned}
& 7(47 \%) \\
& 8(36 \%) \\
& 8(67 \%)
\end{aligned}
$$

GPS 5.0

NetPhos 3.0 at http://www.cbs.dtu.dk/services/NetPhos/(Blom et al., 1999); DIPHOSPH 1.3 at http://www.dabi.temple.edu/disphos/; PHOSPHONET at http://www.phosphonet.ca; and GPS 5.0 at http://gps.biocuckoo.cn (Wang et al., 2020).

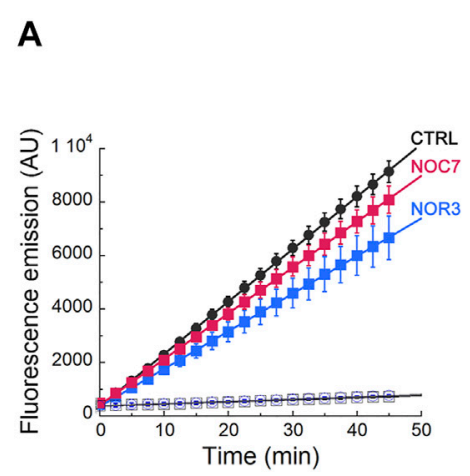

C

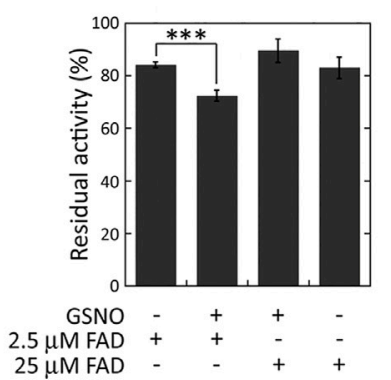

B

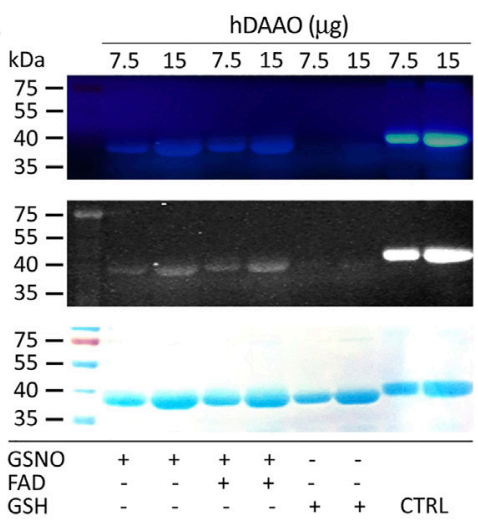

D
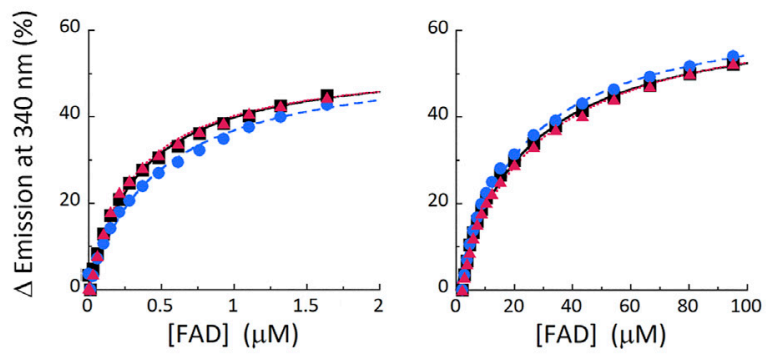

FIGURE 2 | S-Nitrosylation of hDAAO induces partial inactivation. (A) The treatment of U87 cells ectopically expressing hDAAO with the NO donors NOR3 and NOC7 reduced the activity of the flavoenzyme. hDAAO-expressing cells were treated with $50 \mu \mathrm{M}$ NOC7 (red squares), $50 \mu \mathrm{M}$ NOR3 (blue squares), or with an equal amount of DMSO (CTRL, black circles) for $2 \mathrm{~h}$. Cells transfected with the pcDNA3 empty vector and treated with the same amounts of the NO donors (blue open circles) or DMSO (black open square) were used as further controls. In treated and control cells hDAAO activity was detected in cell lysates by the Amplex UltraRed assay and reported as fluorescence emission at $590 \mathrm{~nm}$ over time. Values are reported as mean $\pm \mathrm{SEM}, n=5$. (B) hDAAO is nitrosylated in vitro. The nonreducing SDS-PAGE analysis of recombinant hDAAO (7.5 and $15 \mu \mathrm{g})$ following in vitro S-nitrosylation and the fluorescence switch assay is shown. Mixtures in which the NO donor GSNO was replaced with GSH were analyzed as negative controls whereas the positive controls (CTRL) were represented by protein samples in which all cysteine residues were labeled by the Alexa Fluor $350 \mathrm{C}_{5}$ Maleimide reagent (by omitting the MMTS blocking step during the fluorescence switch assay). Image acquisition was performed by a normal (top panel) and a CCD (middle panel) camera upon excitation of the fluorescent probe. Proteins were also stained with Coomassie blue (bottom panel). (C, D) Nitrosylation slightly alters hDAAO enzymatic stability without affecting the binding of the FAD cofactor. (C) Effect of the presence of GSNO on hDAAO activity, as determined by the oxygen consumption activity assay. In vitro nitrosylation mixtures and related controls were set up in the absence or presence of exogenous $\mathrm{FAD}$ ( 2.5 and $25 \mu \mathrm{M}$ final concentration). Residual activity values (100\% represents the initial activity of the unreacted enzyme) are reported as mean \pm SEM, $n=5$, ${ }^{\star \star \star} p<0.005$, unpaired $t$-test. (D) Analysis of FAD binding to hDAAO apoprotein in the absence and presence of 50 or $500 \mu \mathrm{M}$ of the NO donor GSNO, assessed as protein fluorescence quenching. Values are expressed as percentage of the total change in a single experiment (the determined $\mathrm{K}_{d}$ values are the average of three independent experiments). Left panel shows the interpolation of the experimental data corresponding to the first saturation phase of the protein fluorescence change (up to $2 \mu \mathrm{M}$ of cofactor concentration); right panel reports the same analysis for the second phase of saturation. On the $y$-axis, 100\% correspond to the change in fluorescence emission between the hDAAO apoprotein free form and the fully FAD-complexed one. Measurements were performed at $15^{\circ} \mathrm{C}$. Black squares and continuous lines: control mixture in the absence of GSNO; blue circles and staggered lines: mixture containing $50 \mu \mathrm{M}$ GSNO; red triangles and dotted lines: mixture containing $500 \mu \mathrm{M}$ GSNO.

(GSNO) as a NO donor (or reduced/oxidized glutathione as negative controls). The reaction was also performed after adding $40 \mu \mathrm{M} \mathrm{FAD}$ to push the equilibrium in solution between the apoprotein and the holoenzyme forms of hDAAO toward the latter form. Modified SNO-Cys residues were detected by a fluorescent switch assay in which the SNO-Cys residues were selectively labeled with Alexa Fluor 350 C5 Maleimide. SDSPAGE analysis performed under nonreducing conditions clearly 
TABLE 3 | Effect of nitrosylation or sulfhydration on the FAD-apoprotein hDAAO complex. The cofactor dissociation constants $\left(\mathrm{K}_{\mathrm{d}}\right)$ determined by measuring the protein fluorescence quenching during the titration of the apoprotein with FAD in the absence or presence of different concentrations of the NO donor GSNO or of the $\mathrm{H}_{2} \mathrm{~S}$ donor NaHS, under different buffer conditions.

\begin{tabular}{|c|c|c|c|c|c|c|}
\hline & \multicolumn{3}{|c|}{ GSNO ( $\mu \mathrm{M})$} & \multicolumn{3}{|c|}{ NaHS ( $\mu \mathrm{M})$} \\
\hline & 0 & 50 & 500 & 0 & 5 & 40 \\
\hline \multicolumn{7}{|l|}{ First phase } \\
\hline $\mathrm{K}_{\mathrm{d}}(\mu \mathrm{M})$ & $0.35 \pm 0.02$ & $0.34 \pm 0.04$ & $0.31 \pm 0.02$ & $0.43 \pm 0.02$ & $0.31 \pm 0.03$ & $0.33 \pm 0.02$ \\
\hline Amplitude (\%) & 45 & 46 & 44 & 42 & 50 & 48 \\
\hline \multicolumn{7}{|l|}{ Second phase } \\
\hline $\mathrm{K}_{\mathrm{d}}(\mu \mathrm{M})$ & $24.2 \pm 2.1$ & $23.0 \pm 2.0$ & $26.7 \pm 2.3$ & $\geq 30$ & $27.5 \pm 3.2$ & $27.8 \pm 3.2$ \\
\hline Amplitude (\%) & 55 & 54 & 56 & 58 & 50 & 52 \\
\hline
\end{tabular}

indicated that GSNO modified hDAAO (Figure 2B). No aspecific labeling was observed in the negative control samples. The presence of exogenous $\mathrm{FAD}$ in the $\mathrm{S}$-nitrosylation mixtures did not affect the extent of hDAAO modification, as a similar signal intensity was apparent for the bands corresponding to the protein incubated with GSNO in the presence or absence of the flavin cofactor. The latter observation agrees with the results from DTNB assay, indicating that two cysteines were modified for both the hDAAO apoprotein and holoenzyme forms.

The effect of S-nitrosylation was investigated in vitro by measuring the residual enzymatic activity of recombinant hDAAO upon incubation with the NO donor at two concentrations of FAD corresponding to $25 \mu \mathrm{M}$ (i.e., equimolar to hDAAO concentration) and $2.5 \mu \mathrm{M}$. The latter concentration was selected to reproduce physiological conditions (Decker and Byerrum, 1954; Leighton et al., 1982). A slight, but statistically significant, reduced hDAAO activity was observed in the presence of $2.5 \mu \mathrm{M}$ FAD compared to $25 \mu \mathrm{M}$ FAD or control conditions (Figure 2C, residual acitivity $72 \pm 2,89 \pm 4$ and $84 \pm 2$, respectively, $p<0.005$ ). The protective effect of an equimolar amount of the cofactor suggests that the cysteine residue(s) subjected to $S$-nitrosylation are likely more reactive in the hDAAO apoprotein form. Spectral experiments monitoring protein fluorescence quenching during titration of the hDAAO apoprotein with increasing concentrations of FAD in the presence of 50 or $500 \mu \mathrm{M}$ of the NO donor showed no change in $K_{d}$ values for the apoprotein-FAD complex or in the equilibrium between the two known apoprotein conformations (Murtas et al., 2017) (Figure 2D; Table 3). This result excludes the notion that nitrosylation may affect the interaction of the cofactor with the apoprotein moiety while it does suggest that nitrosylation results in an alteration in hDAAO conformation that partially inactivates the enzyme, a process that is faster for the apoprotein form than for the holoenzyme counterpart.

\section{Human D-Amino Acid Oxidase Sulfhydration Studies}

Cellular studies on U87 cells ectopically expressing hDAAO showed that the enzyme activity significantly increases in cells treated with the hydrogen sulfide donor NaHS compared to controls (Figure 3A, treatment $\times$ time interaction $\mathrm{F}(18,90)=$ $4.331, p<0.0001)$. In vitro sulfhydration reaction mixtures were set up by diluting the recombinant hDAAO $(25 \mu \mathrm{M}$, depleted of the reducing agent), in nonreducing storage buffer added with $40 \mu \mathrm{M}$ FAD: no signal due to protein modification was apparent (Figure 3B), suggesting that hDAAO sulfhydration, if there is any, is below the detection limit.

The incubation of hDAAO with the hydrogen sulfide donor in the presence of a low concentration of exogenous FAD $(2.5 \mu \mathrm{M}$, molar ratio hDAAO:FAD $=1: 1$ ) affected flavoenzyme stability (Figure 3C, top panel): in the control mixture (i.e., in the absence of $\mathrm{NaHS}$ ), residual activity decreased to $59 \pm 3 \%$ after $4 \mathrm{~h}$ of incubation at $37^{\circ} \mathrm{C}$, while it was unchanged in the mixture containing $1 \mathrm{mM}$ NaHS $(92 \pm 14 \%)$. Notably, the same stabilizing effect was obtained by adding an excess of free FAD $(25 \mu \mathrm{M}$, molar ratio hDAAO:FAD $=1: 10)$ instead of NaHS. Differently from GSNO, the hydrogen sulfide donor affected FAD binding to hDAAO apoprotein (Figure 3D): the equilibrium between the two apoprotein conformations is slightly altered by NaHS, and the $\mathrm{K}_{\mathrm{d}}$ values for FAD binding are decreased for both phases (Table 3). Notably, NaHS concentrations in the low $\mu \mathrm{M}$ range are sufficient to induce the observed effect: the tighter hDAAO-FAD interaction observed in the presence of $5 \mu \mathrm{M}$ NaHS increases the amount of active holoenzyme form in solution, thus explaining the observed increase in both enzymatic activity (Figure 3A) and stability (Figure 3C).

\section{Human D-Amino Acid Oxidase Phosphorylation Studies}

As hDAAO was predicted to be phosphorylated (likely by PKA and/or PKC, among other kinases, see above), we analyzed the protein endogenously expressed in human brain tissues using cerebellum lysates (expected to be strongly enriched in hDAAO) and prefrontal cortex lysates (as a negative control) by performing immunoprecipitation experiments. Western blot analysis showed that hDAAO was successfully isolated from the cerebellum lysate, but not from that of the prefrontal cortex (Figure 4A, left), the protein being expressed at very low levels in the latter brain region (Verrall et al., 2007; Sacchi et al., 2008). The Pro-Q Diamond gel staining following SDSPAGE revealed that, in the cerebellum, the flavoenzyme is phosphorylated, although only to a low extent: a faint, positive $40-\mathrm{kDa}$ band corresponding to phosphorylated hDAAO was observed in the immunoprecipitated sample from cerebellum whereas it was absent in the negative controls (Figure 4A, right). 
A

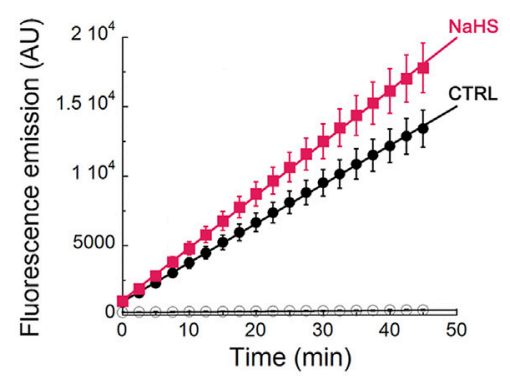

C

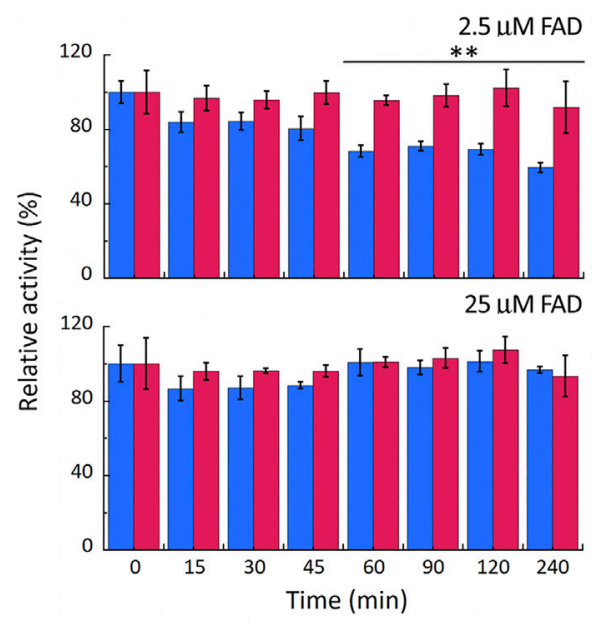

B

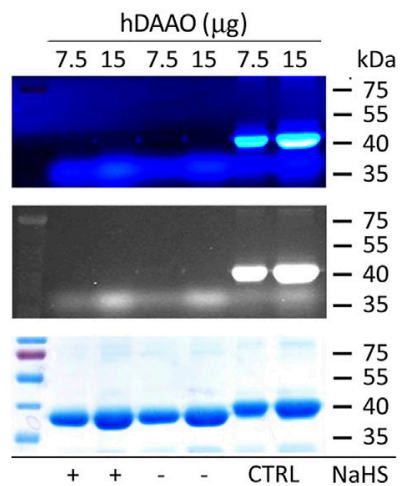

D
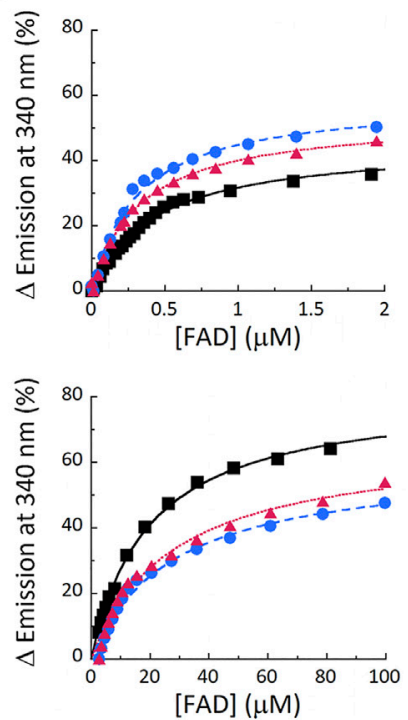

FIGURE 3 | Effect of S-sulfhydration on hDAAO properties. (A) Treatment of U87 transfected cells expressing hDAAO with the hydrogen sulfide donor NaHS increases the activity of the flavoenzyme. Cells were treated with $50 \mu \mathrm{M} \mathrm{NaHS}$ (red squares) or with an equal amount of $\mathrm{H}_{2} \mathrm{O}(\mathrm{CTRL}$, black circles) for 30 min. Cells transfected with the pcDNA3 empty vector and treated with the same amount of the $\mathrm{H}_{2} \mathrm{~S}$ donor (open circles) were used as further controls. In treated and control cells hDAAO activity was detected in cell lysates by the Amplex UltraRed assay and reported as fluorescence emission at $590 \mathrm{~nm}$ over time (0-45 min). Values are reported as mean \pm SEM, $n=5$. (B) hDAAO is not sulfhydrated in vitro. The nonreducing SDS-PAGE analysis of recombinant hDAAO (7.5 and $15 \mu \mathrm{g}$ ) following in vitro S-sulfhydration and the fluorescence switch assay is shown. Mixtures in which the hydrogen sulfide donor NaHS was omitted were analyzed as negative controls whereas positive controls (CTRL) were represented by protein samples in which all cysteine residues were labeled by Alexa Fluor $350 \mathrm{C}_{5} \mathrm{Maleimide}$ (see legend of Figure 2B for details). Proteins were also stained with Coomassie blue (bottom panel). (C, D) The hydrogen sulfide donor NaHS appears to stabilize recombinant hDAAO and affect the FAD cofactor binding. (C) Effect of $1 \mathrm{mM} \mathrm{NaHS}$ on the time course of hDAAO activity, as determined by the oxygen consumption activity assay. In vitro sulfhydration mixtures (red bars) and related controls (blue bars) were set up in the absence or presence of exogenous $\mathrm{FAD}$ ( 2.5 or $25 \mu \mathrm{M}$ final concentration). Residual activity values (100\% represents the initial activity of the unreacted enzyme) are reported as mean $\pm \mathrm{SEM}, n=5$, ${ }^{\star \star} p<0.005$, unpaired $t$-test. (D) Analysis of FAD binding to hDAAO apoprotein in the absence and presence of 5 or $40 \mu \mathrm{M}$ of the hydrogen sulfide donor NaHS, assessed as protein fluorescence quenching. Values are expressed as percentage of the total change. Top panel shows the interpolation of the experimental data corresponding to the first saturation phase of the protein fluorescence change (up to $2 \mu \mathrm{M}$ of cofactor concentration); bottom panel reports the same analysis for the second phase of saturation. Measurements were performed at $15^{\circ} \mathrm{C}$. Black squares and continuous lines: control mixture in the absence of NaHS; blue circles and staggered lines: mixture containing $5 \mu \mathrm{M}$ NaHS; red triangles and dotted lines: mixture containing $40 \mu \mathrm{M}$ NaHS.

We then performed in vitro phosphorylation experiments using fixed amounts of hDAAO (0.17 nmoles/reaction) and three commercial kinases: PKA (0.009 U/reaction), PKC- $\alpha$ (0.001 U/reaction), or PKC- $\varepsilon \quad(0.0005 \mathrm{U} /$ reaction $)$. Positive controls were set up using recombinant cAMP-responsive element-binding protein 1 (CREB1) or histone $\mathrm{H} 1$ in place of hDAAO. The analysis of PKA-treated samples showed a signal stained by the Pro-Q Diamond dye corresponding to the $59-\mathrm{kDa}$ band of the positive control GST-tagged CREB1, whose intensity increased with the time of incubation, while hDAAO was not modified by the kinase (Figure 4B, top). Similar results were obtained for PKC- $\alpha$ - and PKC- $\varepsilon$-treated samples: a band corresponding to the histone $\mathrm{H} 1$ was evident upon staining for phosphoproteins while hDAAO was not detected (not shown). These findings suggest it is unlikely that PKA and $\mathrm{PKC}$ are involved in phosphorylation of the human flavoenzyme. 

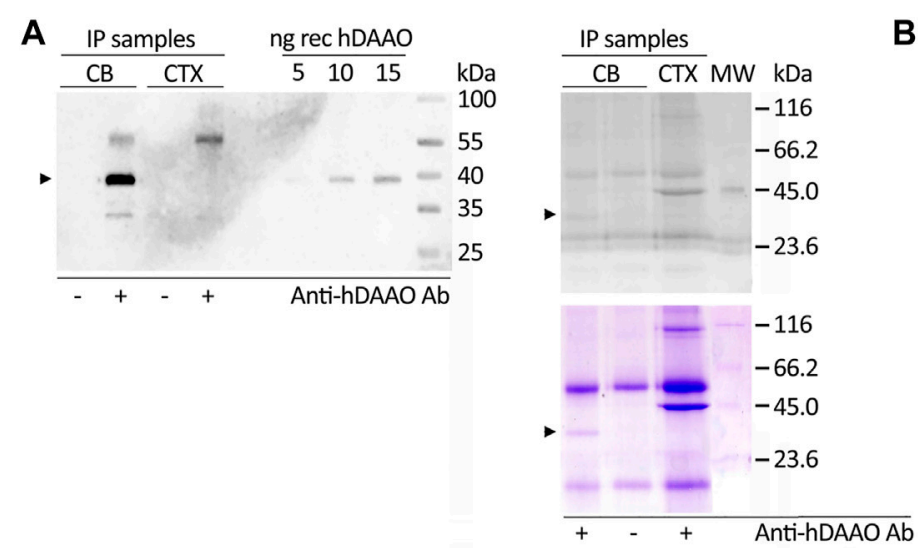

B

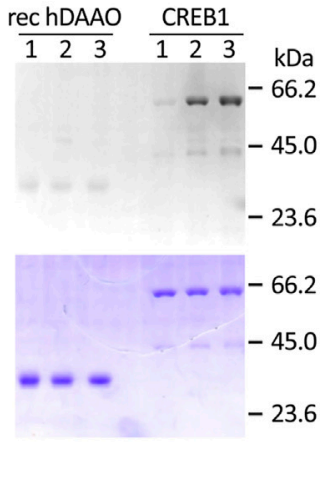

FIGURE 4 | Phosphorylation of hDAAO. (A) In the cerebellum hDAAO is phosphorylated. Left) The flavoenzyme was immunoprecipitated from cerebellum lysates (CB) but not from cortex samples (CTX), as verified by Western blot. Right) The flavoenzyme phosphorylation levels were detected by the Pro-Q Diamond Gel Stain (top panel) and the identity of the observed $40 \mathrm{kDa}$ bands further verified by Coomassie blue staining (bottom panel); in both panels arrowheads indicate the corresponding hDAAO band. Immunoprecipitations performed either on cerebellum lysates in the absence of hDAAO antibodies or on cortex lysates (where the protein is present at trace levels) represented negative controls while diluted PeppermintStick Phosphoprotein Molecular Weight Standards (0.125 $\mu \mathrm{g}$ each protein, MW lane) were used as positive controls. The additional faint bands (at 55 and $30 \mathrm{kDa}$ ) observed in the left panel should correspond to the anti-hDAAO lgG heavy chain and to protein G, respectively. The bands present in right panel, in addition to the $40 \mathrm{kDa}$ one corresponding to hDAAO, are aspecific signals due to proteins interacting with the beads regardless of the presence of the crosslinked antibody. (B) In vitro phosphorylation experiments indicated that hDAAO is not modified by PKA. SDS-PAGE analysis of aliquots of the reaction mixtures containing $2 \mu \mathrm{g}$ of recombinant hDAAO or $1.2 \mu \mathrm{g}$ GST-tagged CREB1 as a positive control, collected at different times of incubation at $30^{\circ} \mathrm{C}$ (1 = 0 min; 2 = 2 h; 3 = overnight). Upon resolution on a 12\% acrylamide gel, phosphoproteins were detected by the Pro-Q Diamond Gel Stain (top panel): while the 59-kDa band corresponding to CREB1 was positively stained, no detectable signal was apparent for the 40-kDa band corresponding to hDAAO. The amount of loaded proteins was verified by subsequently staining the gel in Coomassie blue (bottom panel).

\section{DISCUSSION}

During the last decade, a relevant physiological role was highlighted for hDAAO in the central nervous system: in several areas, it is responsible for catabolizing the key endogenous NMDAr coagonist D-Ser (Sacchi et al., 2012; Murtas et al., 2017; Pollegioni et al., 2018). The flavoenzyme is therefore indirectly involved in modulating the activation state of these receptors and plays a role in NMDAr signaling pathway impairments, which are known to occur in acute and chronic neurological diseases and are often due to an imbalanced D-Ser metabolism (Collingridge et al., 2013; Paul and de Belleroche, 2014; Guercio and Panizzutti, 2018; Kondori eta 1., 2018; Uno and Coyle, 2019; Ploux et al., 2020).

In this context, structural and functional studies performed on recombinant hDAAO unveiled several mechanisms that would modulate the enzyme's properties (see Introduction). Here, we investigated the modulation of hDAAO properties by posttranslational modification(s), as known for SR, the D-Ser biosynthetic enzyme (Mustafa et al., 2007; Raboni et al., 2019). Previous data indicated that, in astrocytes, NO inhibits SR and enhances hDAAO activity, boosting degradation of the neuromodulator (Shoji et al., 2006). S-nitrosylation was recognized as a reversible mechanism of allosteric regulation in several proteins, affecting their functioning, protein-protein interaction, receptor activation, and channel gating (Hess et al., 2005), which could be relevant in pathological conditions (Cho et al., 2009; Foster et al., 2009; Picón-Pagès et al., 2019). Selective protein S-nitrosylation has been linked to the regulation of NMDA and AMPA receptor activity, the surface expression of
AMPA receptors, and D-serine production (Mustafa et al., 2007; Choi et al., 2000; Selvakumar et al., 2009; Selvakumar et al., 2013). The chemical modification of cysteine residues can result from different processes: the direct reaction with $\mathrm{NO}$ followed by oxidation (Hess et al., 2005) and the transnitrosylation either by S-nitrosylated proteins (Nakamura and Lipton, 2013) or by Snitrosylated peptides, (GSNO) being among them (Broniowska et al., 2013). Although we know very little about selectivity for protein cysteine modification, it has been reported that cysteines located in surface-accessible areas with charged amino acids in the vicinity are vulnerable to nitrosylation (Gould et al., 2013). Here, we predicted the highly conserved Cys18 and Cys264 as putative nitrosylation targets as they are located on the surface of hDAAO and surrounded by residues that might stabilize nitrosothiols once formed (Figure 1). Experimental evidence supports this structure-based observation: under native conditions, both the holoenzyme and the apoprotein form of hDAAO possess two solvent-accessible cysteines. hDAAO modification upon in vitro nitrosylation by GSNO was confirmed by the sensitive fluorescent switch assay (Figure 2B) and demonstrated a partial, but significant inactivation of the enzyme (Figure 2C). Accordingly, we reported decreased hDAAO activity in U87 cells ectopically expressing the flavoenzyme treated with two different $\mathrm{NO}$ donors (Figure 2A). Additional in vitro studies showed that the inactivation effect was prevented by an excess of exogenous FAD (Figure 2C). As nitrosylation does not affect the apoprotein-FAD binding equilibrium (Table 3 ), the observed effect is due to the easier reaction of GSNO with the cysteines of the apoprotein of $\mathrm{hDAAO}$, a form which is known to possess a 
"relaxed" tertiary structure characterized by greater exposure of hydrophobic surfaces and increased sensitivity to chemical and thermal unfolding (Caldinelli et al., 2009). Notably, S-nitrosylation of human SR affected its functionality by stabilizing an open, less-active conformation of the enzyme (Marchesani et al., 2020). Thus, this reversible modification might represent a common mechanism for simultaneously controlling both D-Ser metabolic enzymes in different and neighboring cells. In the brain, hDAAO is primarily expressed in the cerebellum astrocytes and Bergmann glia (Verrall et al., 2007). Notably, increased NO levels have been observed during reactive astrogliosis (a condition associated to a wide range of abnormalities and pathologies of the central nervous system) due to the induction of inducible nitric oxide synthase production in "activated" glial cells (Endoh et al., 1994). It is tempting to speculate that increased NO levels in reactive activated glia might lead to hDAAO modification: further investigations are needed to substantiate this hypothesis.

A second post-translational modification of cysteine residues is represented by $\mathrm{S}$-sulfhydration, converting the-SH group of cysteines to a reactive persulfide or-SSH group (Paul and Snyder, 2015; Zhang et al., 2017). Sulfhydration is a highly prevalent modification: a variety of key proteins in different cellular pathways are modified by $\mathrm{H}_{2} \mathrm{~S}$, this affecting crucial cellular processes, including survival/death, differentiation, proliferation, metabolism, mitochondrial bioenergetics/ biogenesis, endoplasmic reticulum stress, inflammation, and oxidative stress (Mustafa et al., 2009; Paul and Snyder, 2012). Here, we observed that the hydrogen sulfide donor NaHS apparently failed in covalently modifying recombinant hDAAO (Figure 3B) although it increased hDAAO activity in U87 cells ectopically expressing the flavoenzyme (Figure 3A) and stabilized the enzyme at a low concentration of FAD (Figure 3C) by inducing a tighter interaction of the apoprotein with FAD (Table 3). This result suggests that NaHS induced stabilization of a protein conformation with the highest avidity for FAD, which explains both the increased stability over time and the highest activity (Figure 3A). Considering that in the mammalian brain endogenous $\mathrm{H}_{2} \mathrm{~S}$ concentrations range between 50 and $160 \mu \mathrm{M}$ (Abe and Kimura, 1996; Wang, 2003), that it can be generated from D-cysteine by the coupled reaction of hDAAO and 3mercaptopyruvate sulfurtransferase (Shibuya et al., 2013), and that an initial protein S-nitrosylation event can potentially promote the formation of a more enduring sulfhydration reaction, the gasotransmitter-mediated modulation of $\mathrm{hDAAO}$ activity might be relevant under specific conditions. Moreover, another enzyme responsible for endogenous $\mathrm{H}_{2} \mathrm{~S}$ production in the brain, i.e., cystathionine $\beta$-synthase (CBS), is predominantly localized in Bergmann glia and astrocytes (Enokido et al., 2005). CBS expression is reduced upon inflammatory activation of astrocytes (Guo et al., 2012) while it is upregulated in acute ischemic conditions (Chan et al., 2015). Once more, we might assume that the consequent variations in $\mathrm{H}_{2} \mathrm{~S}$ levels could differently affect hDAAO functionality.

Phosphorylation represents another post-translational modification common to the enzymes involved in metabolizing the neuromodulator. In murine SR, phosphorylation takes place at multiple sites, depending on the enzyme's cellular localization, but mainly at Thr71, and was shown either to increase or to decrease SR activity (Balan et al., 2009; Foltyn et al., 2010; Vargas-Lopes et al., 2011). The activation of PKC and the resulting SR phosphorylation reduced D-Ser levels in astrocytes and neuronal cultures and in rat frontal cortex (Vargas-Lopes et al., 2011). Here, we observed that hDAAO, which is highly expressed in the cerebellum, is phosphorylated, too, although only to a low extent (Figure 4). However, although in silico analysis suggested that $\mathrm{hDAAO}$ is modified by kinases belonging to the serine/threonine family, in vitro analyses failed to demonstrate high-stoichiometric phosphorylation by PKA or PKC. Further studies are needed to identify the kinase(s) involved and the physiological mechanism related to this posttranslational modification. This is a relevant issue since recent studies reported: i) a relationship between the activation of extracellular signal regulated kinase (ERK) pathway in diabetic retina and DAAO level (Jiang et al., 2021); ii) how an increased D-serine level augmented the activity of nNOS (increasing NO) and thus of the phosphorylated form of GluN1 subunit of NMDAr by PKC in a mouse model of neuropathic pain (Choi et al., 2019); iii) how a decreased D-serine level increased the phosphorylated degree of Akt in motoneurons of SOD1 ${ }^{\text {G93A }}$ mice (Wang et al., 2017) or inhibited the phosphorylation level of GSK3 $\beta$, ERK1/2 and CREB in primary cultured neural stem cells (Huang et al., 2012).

Two main limitations of our study are the need to i) verify the suggested modification of Cys18 and Cys264 in different tissues as well as in U87 cells ectopically expressing hDAAO subjected to different stimuli, and ii) confirm hDAAO phosphorylation in the cerebellum of a statistically significant number of human subjects.

In conclusion, this investigation elucidated novel molecular mechanisms regulating hDAAO functionality, which, intriguingly, are common to SR, i.e., the other enzyme involved in D-Ser metabolism. Based on these findings we argued that evolution likely adopted complicated regulatory strategies to keep the flavoenzyme under stringent functional control (Sacchi et al., 2012; Murtas et al., 2017) and, ultimately, to modulate D-Ser levels in human brain under physiological and pathological conditions.

\section{DATA AVAILABILITY STATEMENT}

The raw data supporting the conclusions of this article will be made available by the authors, without undue reservation.

\section{AUTHOR CONTRIBUTIONS}

SS conceived the work, designed the experimental plan, and wrote the paper. VR and MM performed the experiments under the supervision of SS and contributed to the paper preparation. LP conceived the work, contributed to the analysis and discussion of the results, and critically revised the manuscript. All authors have read and agreed to the published version of the manuscript. 


\section{FUNDING}

This research was supported by Università degli studi dell'Insubria, grant "Fondo di Ateneo per la Ricerca" to SS and LP.

\section{REFERENCES}

Abe, K., and Kimura, H. (1996). The Possible Role of Hydrogen Sulfide as an Endogenous Neuromodulator. J. Neurosci. 16, 1066-1071. doi:10.1523/ jneurosci.16-03-01066.1996

Balan, L., Foltyn, V. N., Zehl, M., Dumin, E., Dikopoltsev, E., Knoh, D., et al. (2009). Feedback Inactivation of D-Serine Synthesis by NMDA Receptor-Elicited Translocation of Serine Racemase to the Membrane. Proc. Natl. Acad. Sci. 106, 7589-7594. doi:10.1073/pnas.0809442106

Blom, N., Gammeltoft, S., and Brunak, S. (1999). Sequence and Structure-Based Prediction of Eukaryotic Protein Phosphorylation Sites. J. Mol. Biol. 294, 1351-1362. doi:10.1006/jmbi.1999.3310

Broniowska, K. A., Diers, A. R., and Hogg, N. (2013). S-nitrosoglutathione. Biochim. Biophys. Acta (Bba) - Gen. Subjects 1830, 3173-3181. doi:10.1016/j. bbagen.2013.02.004

Caldinelli, L., Molla, G., Bracci, L., Lelli, B., Pileri, S., Cappelletti, P., et al. (2010). Effect of Ligand Binding on Human D -amino Acid Oxidase: Implications for the Development of New Drugs for Schizophrenia Treatment. Protein Sci. 19, 1500-1512. doi:10.1002/pro.429

Caldinelli, L., Molla, G., Sacchi, S., Pilone, M. S., and Pollegioni, L. (2009). Relevance of Weak Flavin Binding in Human D-Amino Acid Oxidase. Protein Sci. 18, 801-810. doi:10.1002/pro.86

Cappelletti, P., Campomenosi, P., Pollegioni, L., and Sacchi, S. (2014). The Degradation (By Distinct Pathways) of Humand-Amino Acid Oxidase and its Interacting Partner pLG72 - Two Key Proteins Ind-Serine Catabolism in the Brain. FEBS J. 281, 708-723. doi:10.1111/febs.12616

Cappelletti, P., Piubelli, L., Murtas, G., Caldinelli, L., Valentino, M., Molla, G., et al. (2015). Structure-function Relationships in Human D-Amino Acid Oxidase Variants Corresponding to Known SNPs. Biochim. Biophys. Acta (Bba) - Proteins Proteomics 1854, 1150-1159. doi:10.1016/j.bbapap.2015. 02.005

Ceroni, A., Passerini, A., Vullo, A., and Frasconi, P. (2006). DISULFIND: a Disulfide Bonding State and Cysteine Connectivity Prediction Server. Nucleic Acids Res. 34, W177-W181. doi:10.1093/nar/gkl266

Chan, S. J., Chai, C., Lim, T. W., Yamamoto, M., Lo, E. H., Lai, M. K., et al. (2015). Cystathionine $\beta$-synthase Inhibition Is a Potential Therapeutic Approach to Treatment of Ischemic Injury. ASN Neuro 7, 1759091415578711. doi:10.1177/ 1759091415578711

Cho, D.-H., Nakamura, T., Fang, J., Cieplak, P., Godzik, A., Gu, Z., et al. (2009). S-Nitrosylation of Drp1 Mediates $\beta$-Amyloid-Related Mitochondrial Fission and Neuronal Injury. Science 324, 102-105. doi:10.1126/science.1171091

Choi, S. R., Roh, D. H., Yoon, S. Y., Choi, H. S., Kang, S. Y., Han, H. J., et al. (2019). Astrocyte D-Serine Modulates the Activation of Neuronal NOS Leading to the Development of Mechanical Allodynia in Peripheral Neuropathy. Mol. Pain 15, 1744806919843046. doi:10.1177/1744806919843046

Choi, Y.-B., Tenneti, L., Le, D. A., Ortiz, J., Bai, G., Chen, H.-S. V., et al. (2000). Molecular Basis of NMDA Receptor-Coupled Ion Channel Modulation by S-Nitrosylation. Nat. Neurosci. 3, 15-21. doi:10.1038/71090

Chumakov, I., Blumenfeld, M., Guerassimenko, O., Cavarec, L., Palicio, M., Abderrahim, H., et al. (2002). Genetic and Physiological Data Implicating the New Human Gene G72 and the Gene for D-Amino Acid Oxidase in Schizophrenia. Proc. Natl. Acad. Sci. 99, 13675-13680. doi:10.1073/pnas. 182412499

Collingridge, G. L., Volianskis, A., Bannister, N., France, G., Hanna, L., Mercier, M., et al. (2013). The NMDA Receptor as a Target for Cognitive Enhancement. Neuropharmacology 64, 13-26. doi:10.1016/j.neuropharm.2012.06.051

D’Aniello, A., D’Onofrio, G., Pischetola, M., D’Aniello, G., Vetere, A., Petrucelli, L., et al. (1993). Biological Role of D-Amino Acid Oxidase and D-Aspartate Oxidase. Effects of D-Amino Acids. J. Biol. Chem. 268, 26941-26949. doi:10.1016/s0021-9258(19)74201-x

\section{ACKNOWLEDGMENTS}

We acknowledge the support from Consorzio Interuniversitario per le Biotecnologie.

Decker, L. E., and Byerrum, R. U. (1954). The Relationship between Dietary Riboflavin Concentration and the Tissue Concentration of Riboflavin-Containing Coenzymes and Enzymes. J. Nutr. 53, 303-315. doi:10.1093/jn/53.2.303

Endoh, M., Maiese, K., and Wagner, J. (1994). Expression of the Inducible Form of Nitric Oxide Synthase by Reactive Astrocytes after Transient Global Ischemia. Brain Res. 651, 92-100. doi:10.1016/0006-8993(94)90683-1

Enokido, Y., Suzuki, E., Iwasawa, K., Namekata, K., Okazawa, H., and Kimura, H. (2005). Cystathionine $\beta$-synthase, a Key Enzyme for Homocysteine Metabolism, Is Preferentially Expressed in the Radial Glia/astrocyte Lineage of Developing Mouse CNS. FASEB J. 19, 1854-1856. doi:10.1096/fj.05-3724fje

Fariselli, P., Riccobelli, P., and Casadio, R. (1999). Role of Evolutionary Information in Predicting the Disulfide-Bonding State of Cysteine in Proteins. Proteins 36, 340-346. doi:10.1002/(sici)1097-0134(19990815)36: $3<340$ ::aid-prot8>3.0.co;2-d

Foltyn, V. N., Zehl, M., Dikopoltsev, E., Jensen, O. N., and Wolosker, H. (2010). Phosphorylation of Mouse Serine Racemase Regulates D -serine Synthesis. FEBS Lett. 584, 2937-2941. doi:10.1016/j.febslet.2010.05.022

Foster, M. W., Hess, D. T., and Stamler, J. S. (2009). Protein S-Nitrosylation in Health and Disease: a Current Perspective. Trends Mol. Med. 15, 391-404. doi:10.1016/j.molmed.2009.06.007

Gonzalez, G. A., and Montminy, M. R. (1989). Cyclic AMP Stimulates Somatostatin Gene Transcription by Phosphorylation of CREB at Serine 133. Cell 59, 675-680. doi:10.1016/0092-8674(89)90013-5

Gould, N., Doulias, P. T., Tenopoulou, M., Raju, K., and Ischiropoulos, H. (2013). Regulation of protein function and signaling by reversible cysteine $\mathrm{S}$-nitrosylation. J. Biol. Chem. 288, 26473-26479. doi:10.1074/jbc.R113.460261

Guercio, G. D., and Panizzutti, R. (2018). Potential and Challenges for the Clinical Use of D-Serine as a Cognitive Enhancer. Front. Psychiatry 9, 14. doi:10.3389/ fpsyt.2018.00014

Guo, W., Kan, J. T., Cheng, Z. Y., Chen, J. F., Shen, Y. Q., Xu, J., et al. (2012). Hydrogen Sulfide as an Endogenous Modulator in Mitochondria and Mitochondria Dysfunction. Oxid Med. Cell Longev 2012, 878052. doi:10.1155/2012/878052

Han, P., Zhou, X., Huang, B., Zhang, X., and Chen, C. (2008). On-gel Fluorescent Visualization and the Site Identification of S-Nitrosylated Proteins. Anal. Biochem. 377, 150-155. doi:10.1016/j.ab.2008.03.023

Hess, D. T., Matsumoto, A., Kim, S.-O., Marshall, H. E., and Stamler, J. S. (2005). Protein S-Nitrosylation: Purview and Parameters. Nat. Rev. Mol. Cell Biol, 150-166. doi:10.1038/nrm1569

Huang, X., Kong, H., Tang, M., Lu, M., Ding, J.-H., and Hu, G. (2012). D-Serine Regulates Proliferation and Neuronal Differentiation of Neural Stem Cells from Postnatal Mouse Forebrain. CNS Neurosci. Ther. 18, 4-13. doi:10.1111/j.17555949.2011.00276.x

Jiang, H., Zhang, H., Jiang, X., and Wu, S. (2021). Overexpression of D-Amino Acid Oxidase Prevents Retinal Neurovascular Pathologies in Diabetic Rats. Diabetologia 64, 693-706. doi:10.1007/s00125-020-05333-y

Koga, R., Miyoshi, Y., Sakaue, H., Hamase, K., and Konno, R. (2017). Mouse D-Amino-Acid Oxidase: Distribution and Physiological Ssubstrates. Front. Mol. Biosci. 4, 82. doi:10.3389/fmolb.2017.00082

Kondori, N. R., Paul, P., Robbins, J. P., Liu, K., Hildyard, J. C. W., Wells, D. J., et al. (2018). Focus on the Role of D-Serine and D-Amino Acid Oxidase in Amyotrophic Lateral Sclerosis/motor Neuron Disease (ALS). Front. Mol. Biosci. 5, 8. doi:10.3389/fmolb.2018.00008

Lee, T.-Y., Chen, Y.-J., Lu, T.-C., Huang, H.-D., and Chen, Y.-J. (2011). SNOSite: Exploiting Maximal Dependence Decomposition to Identify Cysteine S-Nitrosylation with Substrate Site Specificity. PLoS One 6, e21849. doi:10. 1371/journal.pone.0021849

Leighton, F., Brandan, E., Lazo, O., and Bronfman, M. (1982). Subcellular Fractionation Studies on the Organization of Fatty Acid Oxidation by Liver Peroxisomes. Ann. NY Acad. Sci. 386, 62-80. doi:10.1111/j.1749-6632.1982.tb21408.x

Luks, L., Maier, M. Y., Sacchi, S., Pollegioni, L., and Dietrich, D. R. (2017a). Understanding Renal Nuclear Protein Accumulation: an In Vitro Approach to 
Explain an In Vivo Phenomenon. Arch. Toxicol. 91, 3599-3611. doi:10.1007/ s00204-017-1970-5

Luks, L., Sacchi, S., Pollegioni, L., and Dietrich, D. R. (2017b). Novel Insights into Renal D-Amino Acid Oxidase Accumulation: Propiverine Changes DAAO Localization and Peroxisomal Size In Vivo. Arch. Toxicol. 91, 427-437. doi:10. 1007/s00204-016-1685-z

Maier, M. Y., Luks, L., Baudendistel, O. R., Wittmann, V., and Dietrich, D. R. (2018). Identification of D -amino Acid Oxidase and Propiverine Interaction Partners and Their Potential Role in the PropiverineMediated Nephropathy. Chem.-Biol. Interact. 281, 69-80. doi:10.1016/j. cbi.2017.12.023

Marchesani, F., Gianquinto, E., Autiero, I., Michielon, A., Campanini, B., Faggiano, S., et al. (2020). The Allosteric Interplay between S-nitrosylation and glycine Binding Controls the Activity of Human Serine Racemase. FEBS J. [Epub ahead of print]. doi:10.1111/febs.15645

Marino, S. M., and Gladyshev, V. N. (2010). Structural Analysis of Cysteine S-Nitrosylation: a Modified Acid-Based Motif and the Emerging Role of Transnitrosylation. J. Mol. Biol. 395, 844-859. doi:10.1016/j.jmb.2009.10.042

Molla, G., Sacchi, S., Bernasconi, M., Pilone, M. S., Fukui, K., and Pollegioni, L. (2006). Characterization of Humand-Amino Acid Oxidase. FEBS Lett. 580, 2358-2364. doi:10.1016/j.febslet.2006.03.045

Mothet, J.-P., Parent, A. T., Wolosker, H., Brady, R. O., Jr., Linden, D. J., Ferris, C. D., et al. (2000). D-serine Is an Endogenous Ligand for the glycine Site of the N-Methyl-D-Aspartate Receptor. Proc. Natl. Acad. Sci. 97, 4926-4931. doi:10. 1073/pnas.97.9.4926

Murtas, G., Sacchi, S., and Pollegioni, L. (2019). Substitution of Arginine 120 in Human D-Amino Acid Oxidase Favors FAD-Binding and Nuclear Mistargeting. Front. Mol. Biosci. 6, 125. doi:10.3389/fmolb.2019.00125

Murtas, G., Sacchi, S., Valentino, M., and Pollegioni, L. (2017). Biochemical Properties of Human D-Amino Acid Oxidase. Front. Mol. Biosci. 4, 88. doi:10.3389/fmolb.2017.00088

Mustafa, A. K., Gadalla, M. M., Sen, N., Kim, S., Mu, W., Gazi, S. K., et al. (2009). H2S Signals through Protein S-Sulfhydration. Sci. Signaling 2, ra72. doi:10. 1126/scisignal.2000464

Mustafa, A. K., Kumar, M., Selvakumar, B., Ho, G. P. H., Ehmsen, J. T., Barrow, R. K., et al. (2007). Nitric Oxide S-Nitrosylates Serine Racemase, Mediating Feedback Inhibition of D-Serine Formation. Proc. Natl. Acad. Sci. 104, 2950-2955. doi:10.1073/pnas.0611620104

Nakamura, T., and Lipton, S. A. (2013). Emerging Role of Protein-Protein Transnitrosylation in Cell Signaling Pathways. Antioxid. Redox Signaling 18, 239-249. doi:10.1089/ars.2012.4703

Paul, B. D., and Snyder, S. H. (2015). $\mathrm{H}_{2}$ S: A Novel Gasotransmitter that Signals by Sulfhydration. Trends Biochem. Sci. 40, 687-700. doi:10.1016/j.tibs.2015.08.007

Paul, B. D., and Snyder, S. H. (2012). H2S Signalling through Protein Sulfhydration and beyond. Nat. Rev. Mol. Cell Biol 13, 499-507. doi:10.1038/nrm3391

Paul, P., and de Belleroche, J. (2014). The Role of D-Serine and glycine as Coagonists of NMDA Receptors in Motor Neuron Degeneration and Amyotrophic Lateral Sclerosis (ALS). Front. Synaptic Neurosci. 6, 10. doi:10. 3389/fnsyn.2014.00010

Picón-Pagès, P., Garcia-Buendia, J., and Muñoz, F. J. (2019). Functions and Dysfunctions of Nitric Oxide in Brain. Biochim. Biophys. Acta (Bba) - Mol. Basis Dis. 1865, 1949-1967. doi:10.1016/j.bbadis.2018.11.007

Ploux, E., Freret, T., and Billard, J. M. (2020). D-serine in Physiological and Pathological Brain Aging. Biochim. Biophys. Acta Proteins Proteom 1869, 140542. doi:10.1016/j.bbapap.2020.140542

Pokala, N., and Handel, T. M. (2004). Energy Functions for Protein Design I: Efficient and Accurate Continuum Electrostatics and Solvation. Protein Sci. 13, 925-936. doi:10.1110/ps.03486104

Pollegioni, L., Campaner, S., Raibekas, A. A., and Pilone, M. S. (1997). Identification of a Reactive Cysteine in the Flavin-Binding Domain ofRhodotorula Gracilisd-Amino Acid Oxidase. Arch. Biochem. Biophys. 343, 1-5. doi:10.1006/abbi.1997.0123

Pollegioni, L., Piubelli, L., Sacchi, S., Pilone, M. S., and Molla, G. (2007). Physiological Functions of D-Amino Acid Oxidases: from Yeast to Humans. Cell. Mol. Life Sci. 64, 1373-1394. doi:10.1007/s00018-007-6558-4

Pollegioni, L., Sacchi, S., and Murtas, G. (2018). Human D-Amino Acid Oxidase: Structure, Function, and Regulation. Front. Mol. Biosci. 5, 107. doi:10.3389/ fmolb.2018.00107
Popiolek, M., Ross, J. F., Charych, E., Chanda, P., Gundelfinger, E. D., Moss, S. J., et al. (2011). D-amino Acid Oxidase Activity Is Inhibited by an Interaction with Bassoon Protein at the Presynaptic Active Zone. J. Biol. Chem. 286, 28867-28875. doi:10.1074/jbc.m111.262063

Raboni, S., Marchetti, M., Faggiano, S., Campanini, B., Bruno, S., Marchesani, F., et al. (2019). The Energy Landscape of Human Serine Racemase. Front. Mol. Biosci. 5, 112. doi:10.3389/fmolb.2018.00112

Sacchi, S., Bernasconi, M., Martineau, M., Mothet, J.-P., Ruzzene, M., Pilone, M. S., et al. (2008). pLG72 Modulates Intracellular D-Serine Levels through its Interaction with D-Amino Acid Oxidase. J. Biol. Chem. 283, 22244-22256. doi:10.1074/jbc.m709153200

Sacchi, S., Binelli, G., and Pollegioni, L. (2016). G72 Primate-specific Gene: a Still Enigmatic Element in Psychiatric Disorders. Cell. Mol. Life Sci. 73, 2029-2039. doi:10.1007/s00018-016-2165-6

Sacchi, S., Caldinelli, L., Cappelletti, P., Pollegioni, L., and Molla, G. (2012). Structure-function Relationships in Human D-Amino Acid Oxidase. Amino Acids 43, 1833-1850. doi:10.1007/s00726-012-1345-4

Sacchi, S., Cappelletti, P., Giovannardi, S., and Pollegioni, L. (2011). Evidence for the Interaction of D-Amino Acid Oxidase with pLG72 in a Glial Cell Line. Mol. Cell Neurosci. 48, 20-28. doi:10.1016/j.mcn.2011.06.001

Selvakumar, B., Huganir, R. L., and Snyder, S. H. (2009). S-nitrosylation of Stargazin Regulates Surface Expression of AMPA-Glutamate Neurotransmitter Receptors. Proc. Natl. Acad. Sci. 106, 16440-16445. doi:10. 1073/pnas.0908949106

Selvakumar, B., Jenkins, M. A., Hussain, N. K., Huganir, R. L., Traynelis, S. F., and Snyder, S. H. (2013). S-nitrosylation of AMPA Receptor GluA1 Regulates Phosphorylation, Single-Channel Conductance, and Endocytosis. Proc. Natl. Acad. Sci. 110, 1077-1082. doi:10.1073/pnas.1221295110

Shibuya, N., Koike, S., Tanaka, M., Ishigami-Yuasa, M., Kimura, Y., Ogasawara, Y., et al. (2013). A Novel Pathway for the Production of Hydrogen Sulfide from D-Cysteine in Mammalian Cells. Nat. Commun. 4, 1366. doi:10.1038/ ncomms 2371

Shoji, K., Mariotto, S., Ciampa, A. R., and Suzuki, H. (2006). Mutual Regulation between Serine and Nitric Oxide Metabolism in Human Glioblastoma Cells. Neurosci. Lett. 394, 163-167. doi:10.1016/j.neulet.2005.10.064

Stamler, J. S., Simon, D. I., Osborne, J. A., Mullins, M. E., Jaraki, O., Michel, T., et al. (1992). S-nitrosylation of Proteins with Nitric Oxide: Synthesis and Characterization of Biologically Active Compounds. Proc. Natl. Acad. Sci. 89, 444-448. doi:10.1073/pnas.89.1.444

Uno, Y., and Coyle, J. T. (2019). Glutamate Hypothesis in Schizophrenia. Psychiatry Clin. Neurosci. 73, 204-215. doi:10.1111/pcn.12823

Vargas-Lopes, C., Madeira, C., Kahn, S. A., Albino do Couto, I., Bado, P., Houzel, J. C., et al. (2011). Protein Kinase C Activity Regulates D-Serine Availability in the Brain. J. Neurochem. 116, 281-290. doi:10.1111/j.1471-4159.2010.07102.x

Verrall, L., Walker, M., Rawlings, N., Benzel, I., Kew, J. N. C., Harrison, P. J., et al. (2007). D-Amino Acid Oxidase and Serine Racemase in Human Brain: Normal Distribution and Altered Expression in Schizophrenia. Eur. J. Neurosci. 26, 1657-1669. doi:10.1111/j.1460-9568.2007.05769.x

Vizcarra, C. L., and Mayo, S. L. (2005). Electrostatics in Computational Protein Design. Curr. Opin. Chem. Biol. 9, 622-626. doi:10.1016/j.cbpa.2005.10.014

Wang, C., Xu, H., Lin, S., Deng, W., Zhou, J., Zhang, Y., et al. (2020). GPS 5.0: An Update on the Prediction of Kinase-specific Phosphorylation Sites in Proteins. Genomics, Proteomics Bioinformatics 18, 72-80. doi:10.1016/j.gpb.2020.01.001

Wang, R. (2003). The Gasotransmitter Role of Hydrogen Sulfide. Antioxid. Redox Signaling 5, 493-501. doi:10.1089/152308603768295249

Wang, S., Circu, M. L., Zhou, H., Figeys, D., Aw, T. Y., and Feng, J. (2011). Highly Sensitive Detection of S-Nitrosylated Proteins by Capillary Gel Electrophoresis with Laser Induced Fluorescence. J. Chromatogr. A 1218, 6756-6762. doi:10. 1016/j.chroma.2011.07.062

Wang, W., Duan, W., Wang, Y., Wen, D., Liu, Y., Li, Z., et al. (2017). Intrathecal Delivery of ssAAV9-DAO Extends Survival in SOD1G93A ALS Mice. Neurochem. Res. 42, 986-996. doi:10.1007/s11064-016-2131-6

Wolosker, H., Sheth, K. N., Takahashi, M., Mothet, J.-P., Brady, R. O., Jr., Ferris, C. D., et al. (1999). Purification of Serine Racemase: Biosynthesis of the Neuromodulator D-Serine. Proc. Natl. Acad. Sci. 96, 721-725. doi:10.1073/ pnas.96.2.721

Xie, Y., Luo, X., Li, Y., Chen, L., Ma, W., Huang, J., et al. (2018). DeepNitro: Prediction of Protein Nitration and Nitrosylation Sites by Deep Learning. 
Genomics, Proteomics \& Bioinformatics 16, 294-306. doi:10.1016/j.gpb.2018. 04.007

Xu, Y., Ding, J., Wu, L.-Y., and Chou, K.-C. (2013a). iSNO-PseAAC: Predict Cysteine S-Nitrosylation Sites in Proteins by Incorporating Position Specific Amino Acid Propensity into Pseudo Amino Acid Composition. PLoS One 8, e55844. doi:10.1371/journal.pone.0055844

Xu, Y., Shao, X.-J., Wu, L.-Y., Deng, N.-Y., and Chou, K.-C. (2013b). iSNOAAPair: Incorporating Amino Acid Pairwise Coupling into PseAAC for Predicting cysteineS-Nitrosylation Sites in Proteins. PeerJ 1, e171. doi:10. 7717/peerj.171

Xue, Y., Liu, Z., Gao, X., Jin, C., Wen, L., Yao, X., et al. (2010). GPS-SNO: Computational Prediction of Protein S-Nitrosylation Sites with a Modified GPS Algorithm. PLoS One 5, e11290. doi:10.1371/journal.pone.0011290

Zhang, D., Du, J., Tang, C., Huang, Y., and Jin, H. (2017). $\mathrm{H}_{2}$ S-induced Sulfhydration: Biological Function and Detection Methodology. Front. Pharmacol. 8, 608. doi:10.3389/fphar.2017.00608
Zhao, M., Sutherland, C., Wilson, D. P., Deng, J., Macdonald, J. A., and Walsh, M. P. (2004). Identification of the Linker Histone $\mathrm{H} 1$ as a Protein Kinase $\mathrm{C} \varepsilon$ Binding Protein in Vascular Smooth Muscle. Biochem. Cell Biol. 82, 538-546. doi:10.1139/o04-053

Conflict of Interest: The authors declare that the research was conducted in the absence of any commercial or financial relationships that could be construed as a potential conflict of interest.

Copyright (C) 2021 Sacchi, Rabattoni, Miceli and Pollegioni. This is an open-access article distributed under the terms of the Creative Commons Attribution License (CC $B Y)$. The use, distribution or reproduction in other forums is permitted, provided the original author(s) and the copyright owner(s) are credited and that the original publication in this journal is cited, in accordance with accepted academic practice. No use, distribution or reproduction is permitted which does not comply with these terms. 